\title{
EDITORIAL
}

\section{Clopidogrel Resistance: An Emerging Problem}

Platelets have a central role in the development of arterial thrombosis and subsequent cardiovascular events. An appreciation of this complex process has made antiplatelet therapy the cornerstone of cardiovascular disease management. Dual antiplatelet therapy with aspirin and clopidogrel has been approved for the secondary prevention of cardiovascular events and is currently part of the postpercutaneous coronary intervention treatment regimen. However, subacute stent thrombosis continues to occur in $1 \%$ to $2 \%$ of patients despite dual antiplatelet therapy 1 .

Despite the impressive and consistent effects of aspirin in reducing adverse events in a variety of ischemic heart disease states, more potent antiplatelet agents, glycoprotein $\mathrm{IIb} / \mathrm{III}$ inhibitors, and thienopyridines have been developed. The thienopyridines irreversibly inhibit ADP binding to the $\mathrm{P} 2 \mathrm{Y} 12$ receptor on the platelet surface. By blocking this receptor, these agents interfere with platelet activation, degranulation, and-by inhibiting the modification of the glycoprotein IIb/IIIa receptor-aggregation. Currently available thienopyridine antiplatelet agents include ticlopidine and clopidogrel and prasugrel ${ }^{2}$. The agents have similar platelet effects and have been shown to be clinically efficacious. However, clopidogrel has largely replaced ticlopidine because of an improved safety profile, with a lower incidence of hematologic complications (neutropenia and pancytopenia) than ticlopidine ${ }^{10}$. The effects of clopidogrel are time and dose dependent, with a ceiling effect at approximately $50 \%$ to $60 \%$ inhibition of platelet aggregation ${ }^{2}$.

The term resistance is problematic in that it has been variably used to indicate failure of an agent to prevent the clinical condition for which it is intended or failure of the agent to achieve the biochemical (pharmacokinetic and/or pharmacodynamic) effect. Because of the complex pathophysiology of ischemic heart disease, involving thrombosis, inflammation, vascular biology, hemodynamics, etc, no single agent can be expected to abolish ischemic events. Furthermore, a patient may have the appropriate platelet response to a given therapy but have recurrent events mediated by nonplatelet factors. For these reasons, it would be reasonable to classify patients who have recurrent events on therapy as having failure of therapy, while limiting the term resistance to those patients for whom the agent does not achieve its pharmacological effect. The key clinical question is what role resistance to an agent plays in failure of therapy.

To identify the failure to achieve a pharmacological effect, one must be able to measure it reliably. Several assays are available to measure platelet function and effects of antiplatelet agents ${ }^{3}$.

Analogous to aspirin resistance, there is no clear and accepted definition for clopidogrel resistance. Studies have shown a dose- and time-dependent variability in response to clopidogrel as measured by optical platelet aggregometry in response to ADP. In a study by Gurbel et $\mathrm{al}^{6}, 96$ patients undergoing elective coronary stenting were monitored before and at multiple time points after standard clopidogrel therapy (300-mg loading dose followed by 75 $\mathrm{mg}$ daily). Clopidogrel resistance, empirically defined as $<10 \%$ reduction in aggregation in response to $5 \mu \mathrm{mol} / \mathrm{L}$ ADP compared with pretreatment values, was seen in $63 \%$ of patients at 2 hours, $31 \%$ at 24 hours, $31 \%$ at 5 days, and $15 \%$ at 30 days $^{6}$. Patients with the highest pretreatment values had the least antithrombotic protection over the first 5 days. In another report, Muller et al ${ }^{7}$ defined nonresponders as those with $<10 \%$ reduction in platelet aggregation to ADP and semiresponders as those with $10 \%$ to $29 \%$ reduction 4 hours after 600-mg clopidogrel load, as no additional effect was seen with this treatment regimen at 24 hours. This study found that to $5 \mu \mathrm{mol} / \mathrm{L}$ ADP, $5 \%$ were nonresponders and $9 \%$ were semiresponders, and to $20 \mu \mathrm{mol} / \mathrm{L}$ ADP, $11 \%$ were nonresponders and $26 \%$ were semiresponders 7 .

Several mechanisms of clopidogrel resistance are possible. Extrinsic mechanisms include inappropriate dosing or underdosing of clopidogrel and drug-drug interactions, including a possible interaction between clopidogrel and atorvastatin ${ }^{11}$. There is a positive correlation of clopidogrel response with CYP3A4 activity (measured by erythromycin breath test) ${ }^{12}$, suggesting that an important mechanism may be variable conversion to the active metabolite. Other potential extrinsic mechanisms could include variable absorption of the prodrug or clearance of the active metabolite. Intrinsic mechanisms could include $\mathrm{P} 2 \mathrm{Y}^{11}$ receptor variability, increase in number of receptors, increased release of ADP, or upregulation of other platelet activation pathways. In contrast to aspirin resistance, there has not previously been a link between clopidogrel resistance as measured by platelet assays and clinical adverse events. 
Several questions arise from the growing literature on clopidogrel resistance. Should patients with ACS or those undergoing PCI routinely have platelet function measured? If so, how should it be measured? What should be considered the appropriate definition of clopidogrel resistance? What therapeutic maneuvers should clinicians undertake when they encounter a patient with clopidogrel resistance? Are there actions that can be taken prospectively to avoid the problem of resistance?

One approach to managing clopidogrel resistance may involve giving higher loading and maintenance doses. Another promising approach may be to utilize alternative thienopyridine agents such as CS-747 (LY640315)13, nonthienopyridine $\mathrm{P} 2 \mathrm{Y}^{11}$ inhibitors such as AR-C69931 MX ${ }^{14}$, or antagonists of other platelet targets. As we learn more about the variable response to antiplatelet drugs, will the time soon come for us to think of antiplatelet agents like antibiotics, tailoring therapy when resistance is observed in the laboratory ${ }^{15}$ ?

Another burning debate is worth to mention; the use of proton pump inhibitors (PPIs) with clopidogrel. We know clopidogrel is a prodrug metabolized in the liver by cytochrome P-450 isoenzymes (CYP2C ${ }^{18}$, CYP3A4 etc.) to produce active form of clopidogrel. The PPIs are eliminated by hepatic route and the polymorphically expressed CYP2 $\mathrm{C}^{18}$ is involved in the metabolism of omeprazole, lansoprazole, rabeprazole, esomeprazole and pantoprazole. These drugs reduces the anti platelet effects of clopidogrel by competitive inhibition of $\mathrm{CYP}_{2} \mathrm{C}^{18}$ isoenzyme. So it is advised not to add a PPI treatment to the antiplatelet dual therapy without formal indication ${ }^{16}$.

\section{Professor Md. Abu Siddique}

Professor

Department of Cardiology

Bangabandhu Sheikh Mujib Medical University, Dhaka

\section{References}

1. Barsky AA, Arora RR, Clopidogrel resistancemyth or reality. J Cardiovasc Pharmacol.Ther. 2006:11(1) 47-53.

2. Patrono C, Bachmann F, Baigent C, et al. Expert consensus document on the use of antiplatelet agents. The Task Force on the Use of Antiplatelet Agents in Patients with Atherosclerotic Cardiovascular Disease of the European Society of Cardiology. Eur Heart J. 2004; 25: 166-81

3. Antman EM, Anbe DT, Armstrong PW, et al. ACC/AHA guidelines for the management of patients with ST-elevation myocardial infarction: executive summary: a report of the ACC/AHA Task Force on Practice Guidelines (Committee to Revise the 1999 Guidelines on the Management of Patients With Acute Myocardial Infarction). Circulation.1999; 100:1016-30.

4. Braunwald E, Antman EM, Beasley JW, et al. ACC/AHA guideline update for the management of patients with unsta- ble angina and non-ST-segment elevation myocardial infarction-2002: summary article: a report of the American College of Cardiology/American Heart Association Task Force on Practice Guidelines (Committee on the Management of Patients With Unstable Angina). Circulation. 2002; 106: 1893-1900.

5. Smith SC Jr, Dove JT, Jacobs AK, et al. ACC/AHA guidelines for percutaneous coronary intervention (revision of the 1993 PTCA guidelines) - executive summary: a report of the American College of Cardiology/American Heart Association task force on practice guidelines (Committee to Revise the 1993 Guidelines for Percutaneous Transluminal Coronary Angioplasty) endorsed by the Society for Cardiac Angiography and Interventions. Circulation. 2001; 103: 3019-41.

6. Savage MP, Goldberg S, Bove AA, et al. Effect of thromboxane A2 blockade on clinical outcome and restenosis after successful coronary angioplasty. Multi-Hospital Eastern Atlantic Restenosis Trial (M-HEART II). Circulation. 1995; 92: 3194-200

7. Gurbel PA, Bliden KP, Hiatt BL, et al. Clopidogrel for coronary stenting: response variability, drug resistance, and the effect of pretreatment platelet reactivity. Circulation. 2003; 107: 29

8. Muller I, Besta F, Schulz C, et al. Prevalence of clopidogrel non-responders among patients with stable angina pectoris scheduled for elective coronary stent placement. Thromb Haemost. 2003; 89: 783-87.

9. Sugidachi A, Asai F, Ogawa T, et al. The in vivo pharmacological profile of CS-747, a novel antiplatelet agent with platelet ADP receptor antagonist properties. Br J Pharmacol. 2000; 129: 1439-46.

10. Storey F. The P2Y12 receptor as a therapeutic target in cardiovascular disease. Platelets. 2001; 12: 197-209.

11. CAPRIE Steering Committee. A randomised, blinded, trial of clopidogrel versus aspirin in patients at risk of ischaemic events (CAPRIE). Lancet. 1996; 348: 1329-39.

12. Saw J, Steinhubl SR, Berger PB, et al. Lack of adverse clopidogrel-atorvastatin clinical interaction from secondary analysis of a randomized, placebo-controlled clopidogrel trial. Circulation. 2003; 108: 921-24.

13. Lau WC, Gurbel PA, Watkins PB, et al. Contribution of hepatic cytochrome P450 3A4 metabolic activity to the phenomenon of clopidogrel resistance. Circulation. 2004; 109: $166-71$.

14. Sugidachi A, Asai F, Ogawa T, et al. The in vivo pharmacological profile of CS-747, a novel antiplatelet agent with platelet ADP receptor antagonist properties. Br J Pharmacol. 2000; 129: 1439-46.

15. Storey F. The P2Y12 receptor as a therapeutic target in cardiovascular disease. Platelets. 2001; 12: 197-09

16. Schwab M, Schaeffeler E, Klotz U, Treiber G. CYP2C19 polymorphism is a major predictor of treatment failure in white patients by use of lansoprazole-based quadruple therapy for eradication of Helicobacter pylori. Clin Pharmacol Ther 2004;76:201-09 